\title{
Impact memes: PhDs HuMor(e)
}

\section{Concetta Papapicco ${ }^{1}$ (D) Giuseppe Mininni ${ }^{1}$ \\ Received: 16 January 2020 / Revised: 4 May 2020 / Accepted: 4 June 2020 \\ (C) Springer Science+Business Media, LLC, part of Springer Nature 2020}

\begin{abstract}
The era of User Generated Content (USG) on Social Networks has invested different areas of human experience, including one of the highest levels of education, i.e., the $\mathrm{PhD}$ grade. As regards the opportunity to "imitate" a virtual content, the phenomenon of Memes (Shifman, J Vis Cult 13(3):340-358, 56) is spreading. The present research aims at the understanding how the online functions and practices of humor signification are featured considering linguistic and visual aspects. In particular it has a twofold goals: a) analyzing which differences emerged in terms of functions and emotions between humor in $\mathrm{PhD}$ Memes on Facebook and Instagram by means of 'diatextual' analysis; b) performing a fine-grained qualitative analysis about rethorical aspects based on linguistic and visual elements of Phd Memes in order to contribute to the field of humor automatic detection. To satisfy these purposes, 70 memes about the $\mathrm{PhD}$ on Facebook and Instagram were collected and, then, analyzed in two levels: (1) the quanti-qualitative, aiming to detect the semi-automatic emotional involvement, expression of humor in "meme discourses"; (2) the semiotic analysis of meme images. The results highlight first of all typical cases of incongruences in automatic and diatextual analysis in coding the effective emotions; furthermore they also show the peculiar function of humor, mediated by communication through memes, which is mainly a kind of 'emotional sharing' consisting in the complaint against a complex and precarious career path; in addition some differences in relation to the type of social media (Facebook or Instagram) are reported.
\end{abstract}

Keywords $\mathrm{PhD}$ memes $\cdot$ Mediated humor $\cdot$ Emotional analysis $\cdot$ Semiotic analysis of imagines Diatextual analysis

\section{Introduction}

The era of User Generated Content (USG) on Social Networks has invested different areas of human experience, including one of the highest levels of education, i.e. the $\mathrm{PhD}$ grade. In fact,

Concetta Papapicco

concetta.papapicco@uniba.it

1 Department of Psychology, University of Bari, Bari, Italy 
Social Networks, like Facebook or Instagram, amplify the possibility of creating content and making sure that they reach a wide audience. Indeed, every user, even a non-expert, can put content online, share it or imitate it. Starting from the opportunity to imitate a virtual content, the viral phenomenon of the "Memes" is increasingly spreading. Conceptually the Meme is 'the minimum cultural unit capable of replication' [56: 341]. The term "meme" was first coined by Richard Dawkins [23], who referred to the birth of an idea that represented the culture of reference and had spread rapidly. Taking the biological metaphor, the meme is compared to a replicating gene.

Declined in the virtual context and, specifically, of the Social Networks, Memes can take different forms. One of the typical functions of Memes, especially on Facebook and Instagram, is the replication of semi-serious images accompanied by humorous phrases. What changes in the case of Memes is the humorous communicative act itself in the Social Networks. The communicative act, as shown in Fig. 1, aims at the creation of this viral socio-cultural product in order to convert the typical laughter of face to face communication into like, reactions, shares or hearts depending on the Social Network.

Interesting for our work is the semiotic perspective of Osterroth [46], which states that the viral Meme on social media is the set of language, image and text. "It has to be emphasized that this kind of meme type can be understood as a multimodal artefact" [32], subject of interest in different disciplines. Taking the theoretical boundary between memetics, psychology and computer science, the study aims to assess how, in a context mediated like Facebook and Instagram, the Memes convey the humorous content regarding a high level of education, such as the $\mathrm{PhD}$.

Why precisely focus on the Doctorate $(\mathrm{PhD})$ since it is a high level of education, but also a critical phase of the academic path because $\mathrm{PhD}$ students are neither a teachers/workers nor a students and thus live a professional experience featured by high uncertainty. This is because, as shown by the study of [57] in which both individual and contextual aspects have been studied, the Phds have low probability of being employed in the academic context. This uncertainty characterizes as intellectual uncertainty and employment uncertainty, which, in most cases, generates altered psychological states of anxiety and distress.

Starting from this psychological description of $\mathrm{PhDs}$, we hypothesize that their use of humor, by means of the particular form of Meme, can be a good way to understand functions, emotions and the rhetorical strategies of online humor. The general aim is in fact to examine if and how online practices can modify humor's functions and signification within the 'memes factory', considering both linguistic and visual signals.

In particular, the present research goals are twofold:

a) if there are differences in terms of functions and emotions on $\mathrm{PhD}$ meme humor depending on the virtual environment in which they are shared/created. The memes can

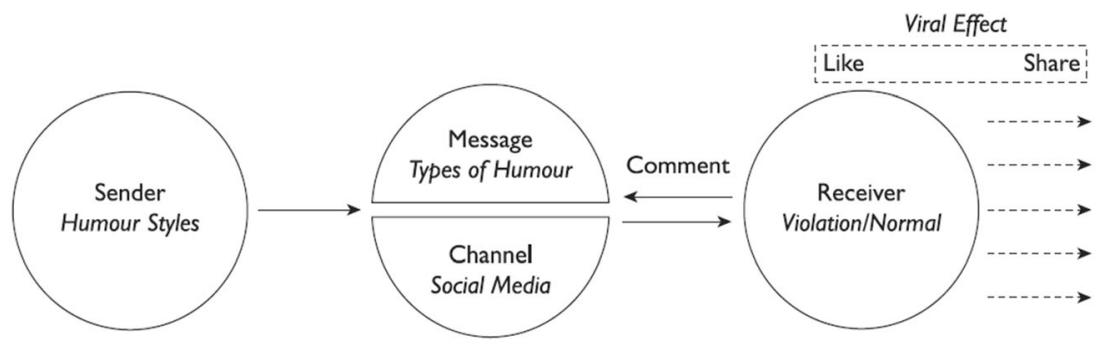

Fig. 1 Framework for the Communication of Humorous Memes [15, 34, 53] 
differ according to the channel through which they are conveyed, since for example Instagram, differently from Facebook, is a more visual social media [9]. This becomes a further objective of the research, namely to understand if the humorous strategies on the $\mathrm{PhD}$ are different in the memes according to the social media (e.g. Facebook or Instagram) through which they are conveyed;

b) to perform a semiotic qualitative analysis of Meme Images in order to give a finer-grained contribution to the improvement of humor automatic detection within computational and artificial intelligence.

To satisfy these purposes, 39 memes about the $\mathrm{PhD}$ were collected from a Facebook page called 'High Impact $\mathrm{PhD}$ meme' and 31 memes about $\mathrm{PhD}$ from "love $\mathrm{PhD}$ memes" Instagram page during the first part of 2019. The $\mathrm{PhD}$ memes were analysed a) by integrating the quantitative and qualitative methods, using both semi-automatic emotional detection and textual analysis for the classification of humour emotions and functions, and, b) a sophisticated semiotic analysis of the meme images to possibly implement, also by visual content, the $\mathrm{PhD}$ humor detection.

From a methodological point of view the present work will use mixed methods consisting in the detection of emotional involvement by means of Tone Analyzer IBM [18], that gives back as output the prevalence of meme emotions analysed through the text. In addition, starting from these quantitative results and considering the $\mathrm{PhD}$ meme texts as "dia-texts" [35], the meme discourses about doctorate path were qualitatively analyzed, evaluating the context of enunciation [42]. Furthermore, the semiotic analysis [61] will take into account the visual part of memes with particular attention to some features like structure, colours and principal characters.

\section{Humor, social network and affective intelligence}

The interest of psychology in humour starts from psychoanalytic theories [25], in which it is underlined the relation to unconscious. Later, Henri Bergson [13] introduces the theory of laughter affirming that the humor behavior is the result of spontaneity and freedom as human values appearing in a rigid or mechanical expression face [12,14]. In this way, humor becomes a psycholinguistic subject of study, defined as a cognitive experience that gives rise to feeling of mirth or joy and it is generally mediated by language [2-4]. Humor is a rhetorical strategy used as a mechanism to reduce sociocultural inhibitions, as in the case of aggressive (verbal) acts [5]. Lowering these defenses, humor has a mainly emotional function, helping the humorist to create a relationship of trust and understanding with the audience. There are three cognitive and emotional theories that aim to explain the functionalities of humor: the "relief theory" [17], for which humor is the result of a liberation resulting from accumulation of energies and tensions; the "superiority theory" [11], evolution of Attardo's aggressive theory, for which every humorous experience arises as an expression of a superiority feeling of a human being towards another human being [8] and the "incongruity theory" [40] according to which humor is the result of the revelation of an unexpected situation inconsistent with the enunciative premises or with one's own thinking about that situation.

According to these theories, therefore, people laugh at situations that they think are unexpected, where the highest quality of communication and relationship [27] is violated, in an inconspicuous way. With these theories, in fact, we emphasize the superiority of the incongruity, purely cognitive faculty, to the emotional or physical sphere. 
Absurdity, nonsense, and surprise are vital themes in humor covered by this theory [39, 62]. According to Berger [10, 11], humor techniques fall into four general categories: language, logic, identity, and action. The interaction of these four categories generates humorous strategies; some examples are summarized in Fig. 2:

As described in the Fig. 2 with the strategies of humor, in the treatise of the literature on humor, our work can be referred in particular to the technique of imitation in verbal humor and landing at the written form.

As far as verbal humor is concerned, various disciplines have been involved: from ethnography to cognitive sciences. The focus of our work, however, will be on the pragmatic, focusing mainly on the theory of incongruity. Within this theoretical field of incongruity, stands out the General Theory of Verbal Humor (GTVH) [17], in which, Yus [64: 502] states that the relationship between humorist and receiver in the humorous communicative act is that of creating a dilemma of incongruity-resolution. This dilemma consists in creating premises and representations of reality by the recipient that are inconsistent with the stakes (enjeu) of the humorous communicative act. When, then, the humorist reveals the real intention of the humorous communicative act, there is a cognitive process of resolution. This imbalance of roles in the communicative act and the lack of respect for the stakes (enjeu) creates the humorous effect. "The breaking of

Humor Technique

Absurditya
Anthropomorphism
Bombasta

Impersonationa

Infantilisma

Ironya

Irreverent behavior
Short Description

Nonsense, a situation that goes against all logical rules

Objects or animals with human features

Talking in a high-flown. grandiloquent. or rhetorical manner

A pursuit or chase of someone or something

Making vigorous arm and $\mathrm{lcg}$ movements or demonstrating exaggerated irregular physical behavior

Lacking dexterity or grace

A coincidental and unexpected occurrence

Misleading the audience by means of a sudden unexpected change of concept

A situation that leads to (minor) disappointment

Someone who deviates from the norms, an odd character

An awkward situation in which someone gets a sense of discomfort, uneasiness, or shame

Making an exaggeration or overstatement; reacting in an exaggerated way; exaggerating the qualities of a person or product

Someone who has a bizarre or monstrous appearance with striking features

Someone acts or behaves in a foolish. naive. gullible. or childish manner

Mimicking or copying someonc's appearance or movements while kecping one's own identity at the same time

Taking on the identity of another person, intentionally or unintentionally

Playing with the sound of words

Saying one thing and meaning something else or exactly the opposite of what you're saying

Lacking proper respect for authority or the prevailing standards

Fig. 2 Humor Techniques $[10,11]$ 
expectations becomes consolidated in terms of relevance, that is, the listener interprets the utterance according to the degree of pertinence that it has in its opinion and rules out the information which is not relevant to interpret the utterance correctly" [64: 504].

According Attardo's [5, 6] approach which is consistent with the General Theory of Verbal Humour (GTVH), there are two distinct moments of the humorous communicative act, that is, humorous comprehension skills and humorous performance. "Therefore, both the speaker and the listener take part in the communicative exchange from a series of linguistic mechanisms in the utterance that help the interlocutor to interpret that utterance properly" ([1], 334). In the initial theory, it was proposed a semantic theory where two semantic patterns were opposed [51]. This has not made it possible to diversify two aspects: semantic and pragmatic humor. And, in addition, it could only be applied to a particular humorous context, that of playful communication, which has a simpler comprehension structure. A different theory is chosen, which refers to more complex communicative contexts, such as monologues and dialogues. Attack, therefore, identifies "six types of knowledge sources exist which make it possible to detect whether a text is humorous or not and show a hierarchical relationship between them. These sources of knowledge namely: "script of opposition"; "the logical mechanism"; "the situation"; "the target"; "the rhetorical strategies" and "the language used" [5, 6:22; 7: 108]. In this context, a logical mechanism is created based on the inconsistency of the interpretative plans by the recipient. "The logical mechanism is the most problematic parameter in the GTVH, since it is the one that surrounds the incongruity-resolution process, and the resolution is optional is some cases of humor" [5, 6:25]; the logical dilemma becomes problematic because the receivers do not always have the contextual sources of information in order to interpret the humorous message. Therefore, starting from the approach of the engagement, we begin to consider the role of the context of enunciation of the humorous act.

"The narrative strategy has to do with the genre being used to express humor; in other words, if it is an imitation, the strategy can adopt a question-answer or riddle format, for instance, although it might also be much more complex and be based on logical mechanisms and reasoning" [45: 605]. Finally, the language contains all the information required in order to be able to verbalize a humorous text, that is, "the speaker has available all the instruments needed for a text to contain the suitable words which lead to an opposition of senses and a double interpretation (polysemy, ambiguity, polyphony, hyperbole, omographical words...)" [45: 606].

Furthermore, 'Attardo points out that humor is different depending on whether it takes place in narrative texts or in conversation" [5, 6: 62]. The essential difference lies in the lack of planning which exists in the latter and in the importance that the context has for a correct utterance interpretation [5, 6: 65]. 'However, the method applied to the analysis of the different humor texts is the same, as it has to do with the identification of the humorous linguistic texts appearing in it, that is, depending on whether they are situated in the plot (jab lines) or at the end (punch lines) of the text. They are identical elements semantically speaking, and the only difference they present is their textual position and their pragmatic function' [5, 6: 82]. 'Therefore, if they appear in the center of the conversation, they help to provide the listener with clues about their humorous intention; In those cases where a punch line appears, the speaker forces the listener to activate a new semantic framework or script to ensure a correct utterance interpretation, which contrasts with the one appearing at the beginning of the text' [5, 6: 83].

In addition to the contribution on the humour linguistic understanding, some recent studies underlined also the import of the visual aspects by showing how bodies, faces, gestures are central in the humor production and understanding. 
D'Errico and Poggi [21] for instance have analysed how both verbal and non-verbal communication contribute to a definition of a 'surface' or 'deep' parody, the first as a superficial function of making laughter, the second one was mainly aimed at strongly criticize and discredit [22] the parody object.

From the situational point of view, humor gets three characteristics in verbal conversation: solidarity, power and psychological needs. "Each one of these functions has its own strategies, thus, firstly, the strategies used by the speaker to show solidarity with humor are: sharing life experiences; highlighting similarities; cooperating in jokes; and joking" [28: 718]. "In this respect, Holmes [30] carry out a study of humor as a social strategy" [30: 160].

This theoretical framework begins to be challenged following the Digital Revolution and the introduction of new media [60], in which a humorous situation has been experienced in a different way. The medium that is often used to channel humour on the Internet and on social media in particular is the medium of the 'Internet meme' [59]. Therefore, computational humor deserves particular attention, as it has the potential of changing computers into a creative and motivational tool for human activity [43, 58].

In particular, the spread of social networks, which offer the possibility of producing a quantity of content very easily, modifies the experience of the humorous communication situation, the function and the comprehension itself of this rhetorical strategy. First of all, the main difficulty regarding the mediated humor is the absence of non verbal communication between enunciators. In fact, this limit engraves the possibility of a fast understanding, such as in the case of mediated irony [48]. More, regarding the communication act that takes place in virtual space, it is often difficult to re-build the context of enunciation: this is another factor of engraving the comprehension. In the specific virtual space, as Social Network, the communication act is transmitted in a "broadcasting" way, reaching a wide audience $[37,38]$. This means that users that know the enunciation context may understand easily the meaning of communication act, on the contrary, there was no effect of joy and mirth in the humorous meaning.

Currently, the studies about Artificial Intelligence (AI) and Natural Language Processing (NLP) focused on the creation of sophisticated software [44], able to detect and recognize the tone and the basic emotions of all discourse genres, also the humoristic one. Humor recognition software, which becomes 2.0 humor, is based on the creation of classifiers [41], capable of identifying humorous and non-humorous text. It is the case of IBM tools, in particular the Tone Analyzer, that is more than an Artificial Intelligence, because it may be classified as Affective Intelligence [47]. The way these software operate is the same: they make a match between the internal vocabulary and the input text, returning, as output, a data of total emotion on the base of a scale with score lower than 0,50, equal to 0,50 and higher than 0,50: the significant values are those higher than 0.50 . The emotions detected are the five basic emotions, which are: joy, fear, sadness, disgust and anger. Joy or happiness represent three shades of enjoyment, satisfaction and pleasure. There is a sense of well-being, inner peace, love, safety and contentment; while fear is a response to impending danger [16: 720]. Fear is a primitive emotion that aims at survival, in relation to a negative environmental stimulus. It can have different levels: from mild state of alarm to real phobia. Sadness, on the other hand, indicates a feeling of disadvantage or loss, but it also occurs in relation to a social withdrawal of the person and the flattening of the mood. Anger triggers a vindication mechanism in relation to a situation of injustice. If anger is active, in the sense that you are having an anger attack, the individual attacks the target, verbally or physically. If anger is passive, the person silently sulks and feels tension and hostility [29]. But, even in these cases, the main limit is that 
it is impossible reduce the complexity of human experience in a matching: in particular the AI is not able to detect the rhetorical strategies and context of enunciations, above all the ones implied in playful communication.

\section{PhD context and social network}

PhDs (philosophiæ doctors) are young researchers who invest 3 or 4 years in the in-depth study of specific scientific topics. These are graduates with different educational backgrounds, from engineers, doctors to more humanistic disciplines such as social sciences, philosophy and literature. They are, however, people who, after completing their university studies, transform their "thirst for knowledge" into an occupation.

However, it is an occupation that is more "vulnerable" to the labor market flexibility logics, in a context, such as the academic one and, on a larger scale, the scientific one, which is based on rigor and quantity. In addition to this, there is a lack of clarification in the definition of who, in terms of skills and tasks, is a "doctoral student". In most cases, it is a paid "qualified" student, but not all $\mathrm{PhDs}$ are eligible for financial support. The common element is that all those who undertake this career clash with an uphill path, not always linear and characterized by deadlines, pressures, measurements of their work through purely quantitative indices, all surrounded by the uncertainty of the future.

This landscape has aroused the interest of sociologists, psychologists and economists, who, starting from statistics, have begun to study doctoral students, with "research in research". In particular, a Belgian research, published in Research Policy, focused on the relationship between the academic career and the mental health of the doctoral students [33]. Specifically, 3600 Belgian doctoral students of all disciplines were involved and it emerged that, independently of training, one third of the sample had a high risk of developing, above all, depression. Despite this, there are no other studies to confirm the data, as most of the results show a correlation with stress and states of anxiety, mainly identified as a concern for the future, due to the lack of prospects. There is also the absence, in the universities themselves, of professionals who deal with supporting Human Resources in future employment or simply accepting individual and collective difficulties and needs. Some strategies, already present within the Social Networks, useful to defuse the common practices of meaning related to the doctorate, are the international humorous pages, in which every $\mathrm{PhD}$ student is recognized. These pages, like many virtual communities, have almost a "mutual help" function, because, thanks to sharing, it is possible to feel less alone.

This is the case of a specific communication tool, which is becoming a rapidly spreading cultural artifact, i.e. the "Meme". The meme is composed of two communicative elements: one visual and the other textual.

\section{Impact PhD meme: a case study}

The study has goals of performing a fine-grained qualitative analysis, considering textual and visual aspects, of Phd Humor that can contribute to field of humor automatic detection; furthermore it will observe differences in terms of functions on $\mathrm{PhD}$ meme humor between Facebook and Instagram. To satisfy these purposes, in the study, 39 memes about the $\mathrm{PhD}$ were collected from a Facebook page called "High Impact $\mathrm{PhD}$ meme" and $31 \mathrm{PhD}$ memes 
from "love PhD memes" Instagram page during the first part of 2019. In fact, more recent $\mathrm{PhD}$ memes have been chosen. The PhD memes were analyzed in two levels: the quanti-qualitative, aiming to detect the semi-automatic emotional involvement, expression of humor in "meme discourses"; the semiotic analysis of meme images to understand if it is possible to classify $\mathrm{PhD}$ humor, also in relation to the type of virtual environment in which memes are built, i.e. Facebook or Instagram.

\subsection{Facebook vs Instagram: a brief netnography}

Facebook and Instagram are two popular social networks, born for different needs and functions. A reflection deserves the names of the two social networks, which are evocative of their functions. Facebook is literally a book of faces, it becomes popular worldwide as a virtual social aggregator and a means of User Generated Content. Instagram, on the other hand, is a visual social network, consisting mainly of images, as announced by the name itself which refers to "Instantaneous photogram".

Facebook has beaten all kinds of competition between social media and since its inception it has gone from being a tool to stay in touch with friends to a total platform, where to look for news, comment and share all kinds of content. Every person can keep a diary of events on Facebook and decide with whom to share them, s/he can publish photos, videos, words and links from external sites and give "likes" to posts shared by friends or even by the pages followed. Facebook is a platform for networking and connecting with friends, its main purpose is to stay connected with the people you know and chat with via the Messenger. Instagram was born first of all as a smartphone application for sharing photos and images. Currently, Instagram also allows you to share videos and publish stories, which have become the strong part of the social network [9]. The stories, which are also present in Facebook but are much less used, allow you to share special moments and are different from normal posts because they disappear after $24 \mathrm{~h}$. Regarding the purely visual aspect, Facebook and Instagram have big differences, especially in the two social media policies of "posting" or "creating" visual content or memes. Instagram works like Facebook but it's mainly a photo sharing application.

According to Shifman [56], internet memes are indicative of an active internet culture and are an important element of civic participation in digital media. The images and videos share common characteristics, are distributed online by numerous of participants, and are created with awareness of other images and videos that are regarded as belonging to the same group of memes. Wiggins [63: 453] defines an internet meme as a 'remixed, iterated message that is rapidly diffused by members of participatory digital culture for the purpose of satire, parody, critique, or other discursive activity.'

The evolution of technology and creativity, however, has allowed us to program apps outside the two social networks, through which users, even non-experts, can generate memes, starting from images already present in the app's database, or you can import photos, on which you can write the text. One of these apps, which can be downloaded for free on the Android system, is a meme generator. The app is useful for creating memes from originals and creatives, to be shared also on the Instagram pages, where the policy and the structure prevent, in the specific case of memes, the creation directly from the social media.

Launching the app from your smartphone, you can access a meme image selection section, as shown in Fig. 3, broken down by theme, popularity, news and preferences. Alternatively, there is the possibility of taking a photo that becomes the visual basis of the meme. 


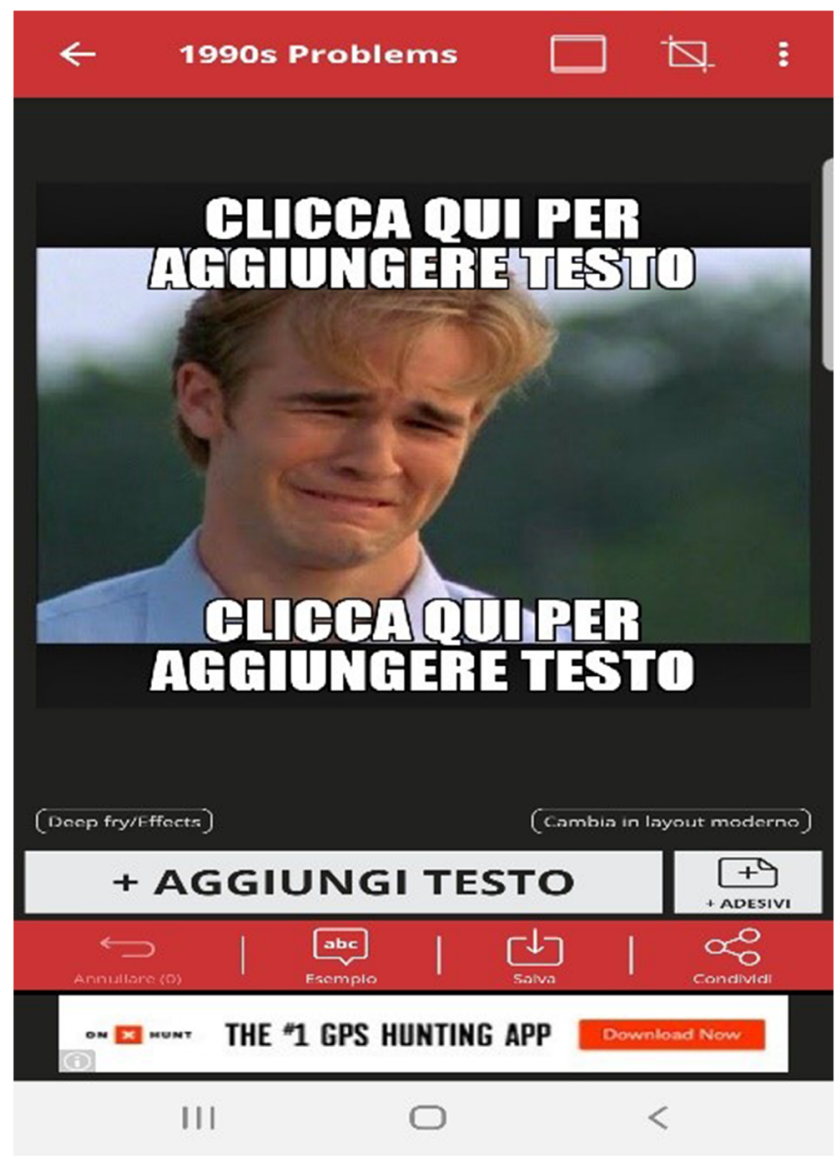

Fig. 3 Layout for inserting text into the image

After choosing the visual part of the meme, as shown in the previous figure, it is possible to create and personalize the meme, based on different themes concerning different areas of human experience, including the highest level of education, namely the $\mathrm{PhD}$.

\subsection{Emotional analysis}

The $\mathrm{PhD}$ memes were analyzed in two levels: the quanti-qualitative, aiming to detect the semiautomatic emotional involvement, expression of humor in "meme discourses"; the semiotic analysis of meme images to understand if it is possible to classify $\mathrm{PhD}$ humor, also in relation to the type of virtual environment in which memes are built, i.e. Facebook or Instagram. The expression of humor were detected by means of an Emotional Analysis software of the IBM group, called Tone Analyzer [31]. By convention, following the model of Barrett and Russell [54] which disfigures positive emotions from negative emotions, the results of positive emotions (joy) have been given a value of 1; for negative emotions (anger, sadness, disgust and fear) a value equal to -1 and for neutrality a value equal to zero. Furthermore, we added a manual coding of emotions, that was carried out by means of two PhD students of different ages and gender. They coded $\mathrm{PhD}$ memes collected by Facebook and Instagram. Applying 
Cohen's K concordance index formula, there is an excellent level of agreement among them $[K=0,82$; because the value of $K$ is included between 0,81 and 1$]$. Specifically, it is noted that a greater agreement on emotional scoring of $\mathrm{PhD}$ memes is obtained on Facebook with 37 agreements on 39 meme texts. While slightly lower is the deal on Instagram with 27 agreements on $31 \mathrm{PhD}$ meme discourse.

From the automatic Emotional Analysis of the $\mathrm{PhD}$ memes emerges a significant prevalence of neutrality on Facebook (64\%) and negativity for Facebook PhD memes (20\%). In the Phd memes texts sample of Instagram there is a prevalence of positivity (90\%) and negativity (7\%) (Graph 1).

The results show the prevalence of neutrality of humor in $\mathrm{PhD}$ Memes on Facebook and a prevalence of positivity in $\mathrm{PhD}$ memes on Instagram. There is, in fact, a significant difference between the emotionality distribution of $\mathrm{PhD}$ memes' humor on Facebook and Instagram $\left[\chi^{2}\right.$ (9) $=33,8 ; p<.001]$.

In particular, the fact that positive emotions are lower on Facebook than Instagram. This can be interpreted in light of the fact that Facebook is a social network that tends to be more associated to the verbal side, where words are preferred to images than Instagram, where the visual aspect predominates over words. Different is also the potential audience for which the memes are thought, as on Facebook there is a more varied audience in terms of age, as opposed to Instagram which is a more youthful social. However the low positivity on Facebook is an interesting trend because, from the psycholinguistic literature on "humor" we expected a positive emotions while in this case the emotional expressivity of this rhetorical strategy is not always linked to positive emotions.

Starting from this limit and considering the memes discourses as "diatexts" [55], whose meaning derives from the interweaving of text and context, it can be noted that the emotionality detected by the Artificial Intelligence is not entirely incorrect, as in the following example:

Eg. 1 "When your manuscript comes back with major revisions. (fear 0,51)

Ah shit, here we go again (anger 0,73)"

In this case, the real fear emerges of those who submit a scientific work in the form of an article to a journal and receive it with many corrections to be made, perhaps, in a limited

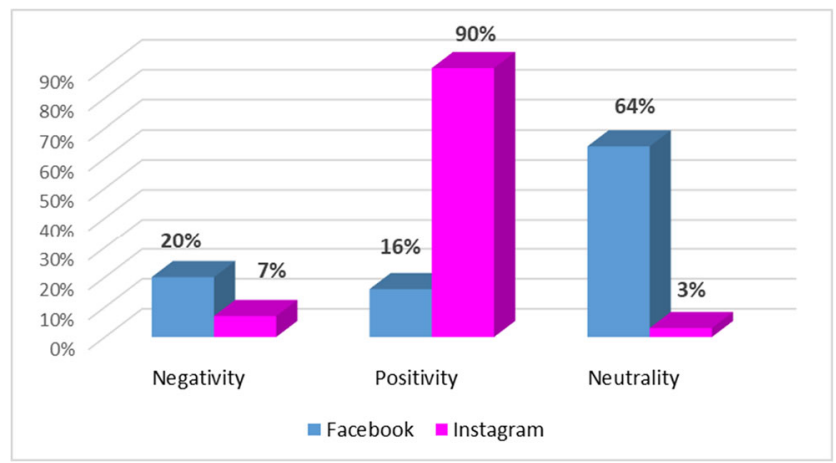

Graph 1 Quantitative results of Emotional Analysis of Memes "High Impact $\mathrm{PhD}$ meme" (Facebook page) and "love $\mathrm{PhD}$ memes" (Instagram page) 
period. Fear is immediately replaced by the anger that emerges in having to work again on the same research, further modifying what could have been the initial idea.

At the textual level, in the memes on the doctorate it can be noted the constant presence of bad words, such as "shit", "bastards" which then load the emotions in a negative sense. On the contrary, in the case of joy detection, this is due to the use of intensifiers, as in the following example:

Eg. 2 "When your manuscript is finally revised gets backfrom review" (joy 0,74)

Also in this case, the basic theme is the review of scientific articles by journals. The use of the "finally" intensifier loads the sentence of joy.

The prevalence, instead, of positivity on Instagram is given by a sense of satisfaction, as in the following extract:

Eg. 3 "Me, enjoying my guilty pleasure of searching my own name in PubMed just to see how the publications are doing" (joy 0,78 )

From these initial results it can be deduced that the $\mathrm{PhD}$ practices of significance are the subject of the memes concern the relationship with the supervisors, the difficulties in publishing the papers and the post-doc uncertainty, as shown in these examples:

Eg. 4 "Phd supervisor: is your manuscript finished yet?

PhD: Well, yes, but actually no"

Eg. 5 "Pimples? Zero

Blackheads? Zero

Probability of your manuscript acceptance on first submission? Zero

Eg. 6 'Me: I'm doing a PhD

People: and then what?

Me: Good question."

In these examples, there is a prevalence of neutrality, linked to a lack of emotions or to the presence of contrasting emotions, i.e. anger and joy in the same phrase. In $\mathrm{PhD}$ meme discourses, neutrality is also due to the presence of imagines, that sometimes is the real element of joy. When in fact the image is central for the meaning, the system detects mainly 'neutrality' in terms of emotions. Therefore, it is necessary analyse $\mathrm{PhD}$ meme images that, in most cases, replace the verbal communication act.

It becomes, therefore, necessary to evaluate the performance of the individual emotions automatically detected both for Facebook and for Instagram. There is a prevalence of neutral text memes on Facebook (neutrality 64\%). While on Instagram there is a greater presence of joy (joy 90\%). For the other emotions, there is, however, a significant trend $\left[\chi^{2}(4)=40,7 ; p<.001\right]$ : sadness is $8 \%$ on Facebook and $3 \%$ on Instagram; anger is $10 \%$ on Facebook and $4 \%$ on Instagram; fear is $2 \%$ on Facebook and $0 \%$ on Instagram (Graph 2).

Interesting is the contrast between the two social media, in terms of positive emotionality from one side and absence of emotionality from the other one. You could, in fact, assume that Instagram Phd memes are more humorous than Facebook.

Going to see the emotionality identified by the judges manually, it is notably a prevalence of neutrality (54\%) and positivity (joy: 44\%) for Facebook while joy (29\%) and anger (29\%) or neutrality $(26 \%)$ for Instagram Meme. Less high are the other emotions like sadness and fear even if higher compared to the automatic detection (Graph 3). 


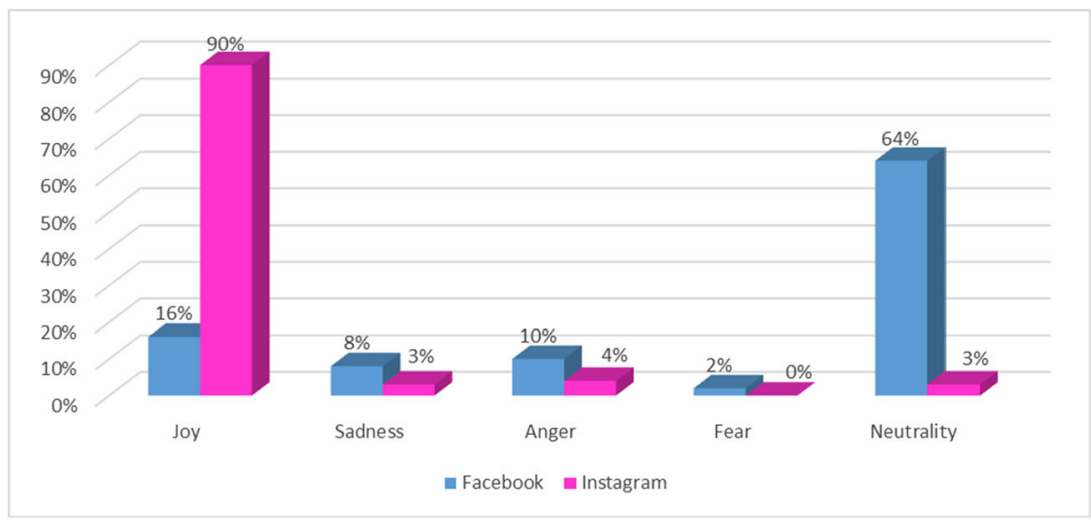

Graph 2 Automatic detection of Emotions of Humor on Facebook and Instagram PhD Memes

The first thing you notice from the transition from automatic detection to the manual one of the judge is that joy is reversed in manual detection: there is a prevalence of joy on Facebook, on the contrary, the software detects a prevalence of joy on Instagram. The same thing happens in the detection of negative emotions (sadness, anger, fear). Neutrality and, therefore, the absence of emotionality has the same trend in automatic and in the manual detection .

In this diversity of perceived emotionality, it is shown that 2.0 humor in Phd memes is predominantly oriented to neutrality and positivity, with the function of social sharing and creating a bond of trust with the potential audience. This, on the one hand, enrich the scientific literature on humor, according to which the valence of humor is always positive [24]. On the other hand, negative emotionality can be typical of the humorous context related to the Meme on Phds with the function of denouncing a situation [21, 49], but also of sadness understood as ridiculing the figure of the Phd, which must struggle with a precarious working environment.

To deepen the potential complexity of $\mathrm{PhD}$ Humor detection, it is necessary also to focus on the visual aspect of the memes, as a possibility of constructing the meaning associated to the text context.

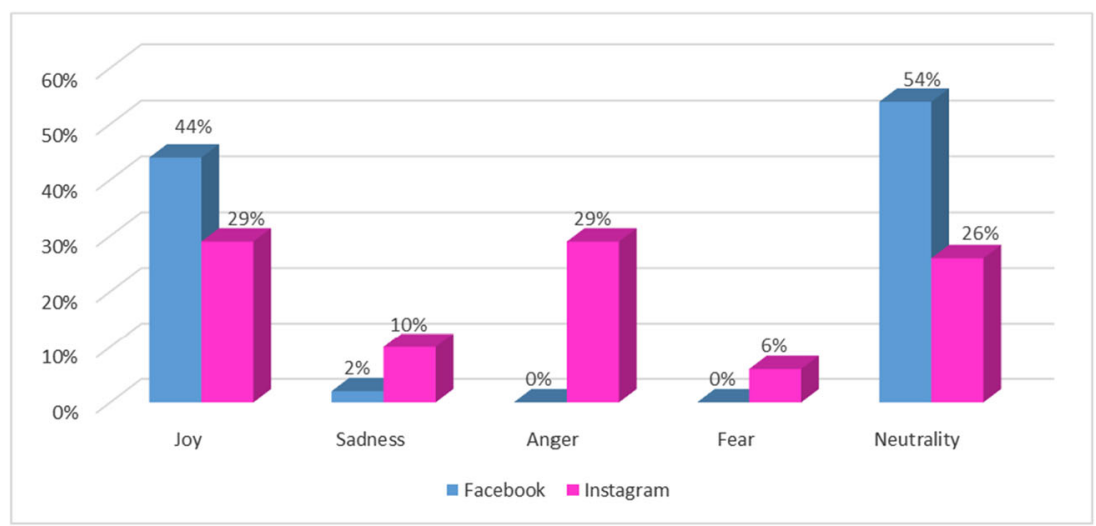

Graph 3 Detection of Emotions of Humor on Facebook and Instagram PhD Memes 


\subsection{Semiotic analysis of PhD meme images}

Sight is one of the most attractive senses of the human being, as it communicates messages immediately with respect to the written text. An image is the privileged and mediated way to pass quickly from the level of the signifier (plan of the expression) to that of the meaning (plan of the content). Also humor expression can be composed by the integration of content and type of expression [21, 50] In this perspective, the semiotic analysis of images [61] is a methodology that allows to trace meanings within visual objects and it is based on the plastic analysis of the image [26] that includes three levels:

1. topological organization, where the constitutional elements of the image are identified;

2. eidetic organization, where the lines of the visual object analyzed are highlighted;

3. chromatic organization.

After having identified these three characteristics, it can be found the plastic formats that allow to reach the content, that is the transition from the signifier to the meaning, which are divided into two aspects:

1. the symbolic correlation, it is the set of conventions that a culture creates and binds to the expressiveness (for example if the color of gold indicates sacredness, the subject / object depicted that clothes gold, will be a sacred subject / object);

2. the semi-symbolic correlation, these are elements of connection between the category of expressiveness and one of its contents (for example topological category, may correspond to one of the contents in which "high" fits to "sacred" and "low" to "profane")

The application of this methodology aims to understand the presence or absence of regularity on the creation of visual aspect in $\mathrm{PhD}$ memes.

First of all, the visual aspect becomes the real imitation element in the "meme" phenomenon. The images used are actually known. These are images that represent clear (chromatic organization) and identifiable subjects (eidetic organization), placed in the foreground (topological organization). In some cases, the presence of dialogues is recorded and therefore the image is a vignette, where all the characters have an equal portion of space. Even the colors are clear in most cases, so they can be easily recognized. As for the subjects and the situations portrayed, the protagonists of the photos are famous movie characters with expressions consistent respect to the text of the image. In the case of $\mathrm{PhD}$ memes, the recurring expressions in the characters is doubt and sadness, as shown in the following examples (Figs. 4 and 5):

As can be seen from the images, the visual aspect helps the comprehension of the text and completes it. Furthermore, they are well-known TV personalities (semi-symbolic correlation level): in the first case the expression of doubt and the sentence of the protagonist are not original, that is to say that the context in which they are inserted changes, which makes it possible to consider it an imitation and detect the basic humor. In the second case, the expression of original sadness of a well-known protagonist of a TV series for teenagers, is set in a different context, where, however, the image is coherent.

Other characters typical of the meme images on the $\mathrm{PhD}$ are the protagonists of cartoons, as in the following examples (Figs. 6 and 7):

The images, however, are not chosen randomly. In example 5 there is an "ogre" (symbolic correlation) in the foreground, which in traditional culture is considered a monstrous figure, 


\section{"PhD is better because you're working what you love"}

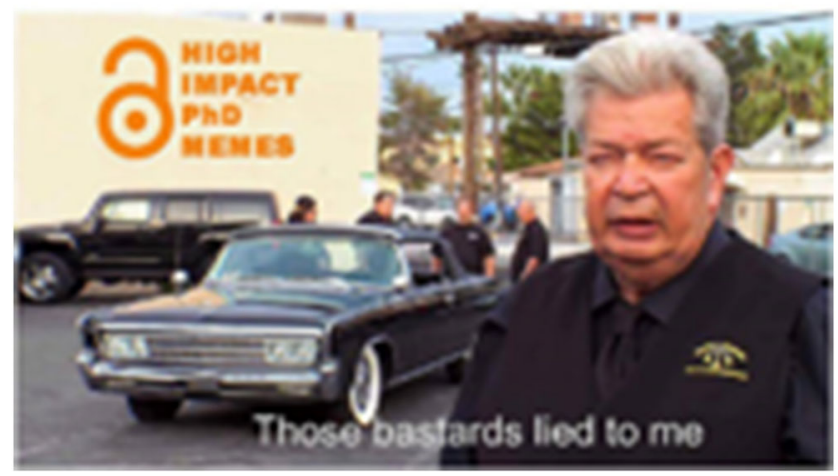

Fig. 4 Example of doubt

here instead replaced by an ogre of modern cinematography used to overturn many of the fairy tales elements. The humor of the $\mathrm{PhD}$ meme fits into this reversal.

Compared to Facebook, the $\mathrm{PhD}$ memes on the Instagram page have no structural differences: the colours are always clear (chromatic organization), with recognizable characters (topological and eidetic organization), what changes is the semantic level. In fact, in choosing the characters, what is recent is privileged on Instagram. The characters that meet the criterion of immutability are the protagonists of the most recent films, as in the following example, in which a scene from the movie "The Joker" is portrayed (Fig. 8).

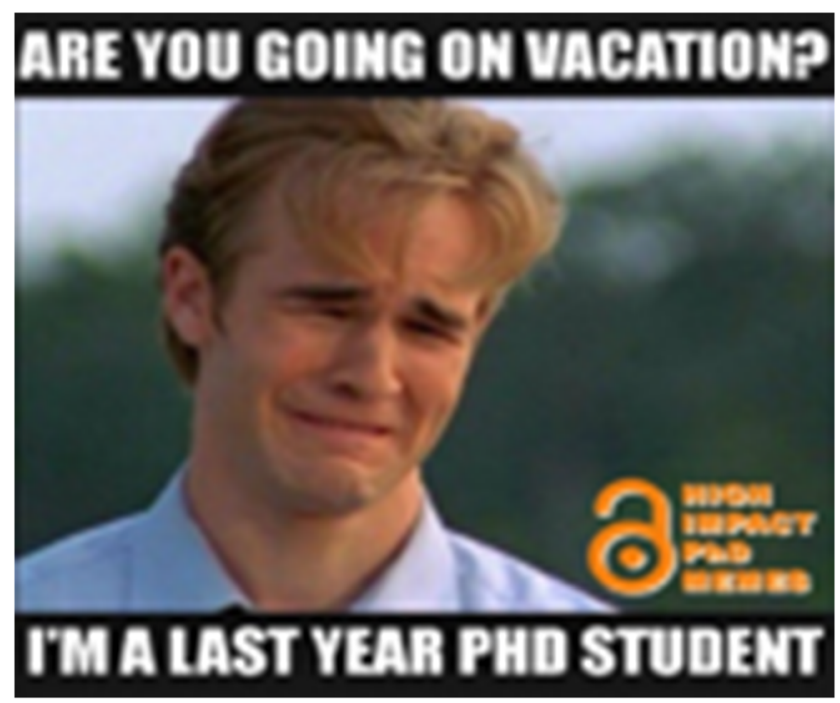

Fig. 5 Example of sadness 


\section{Me: I'm doing a PhD \\ People: and then what?

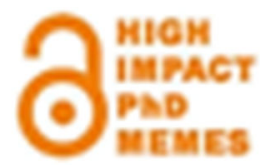

Me:

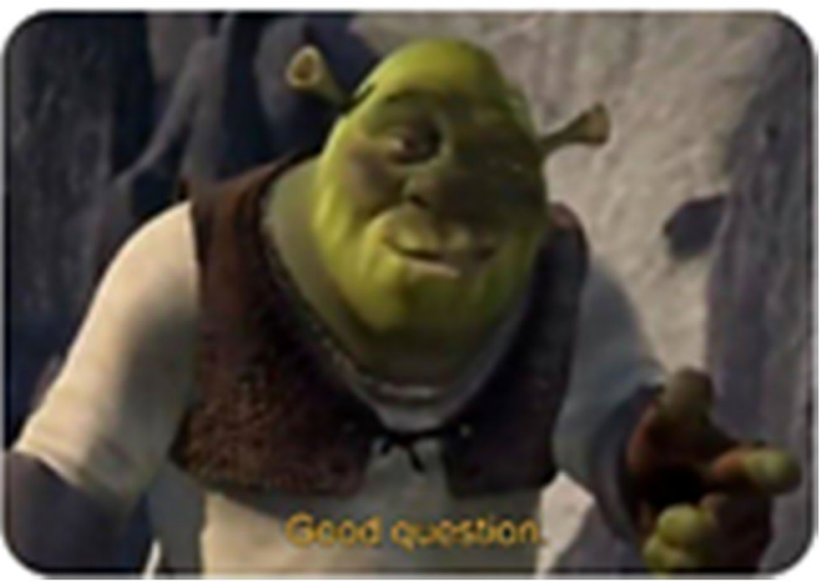

Fig. 6 Meme of Shrek

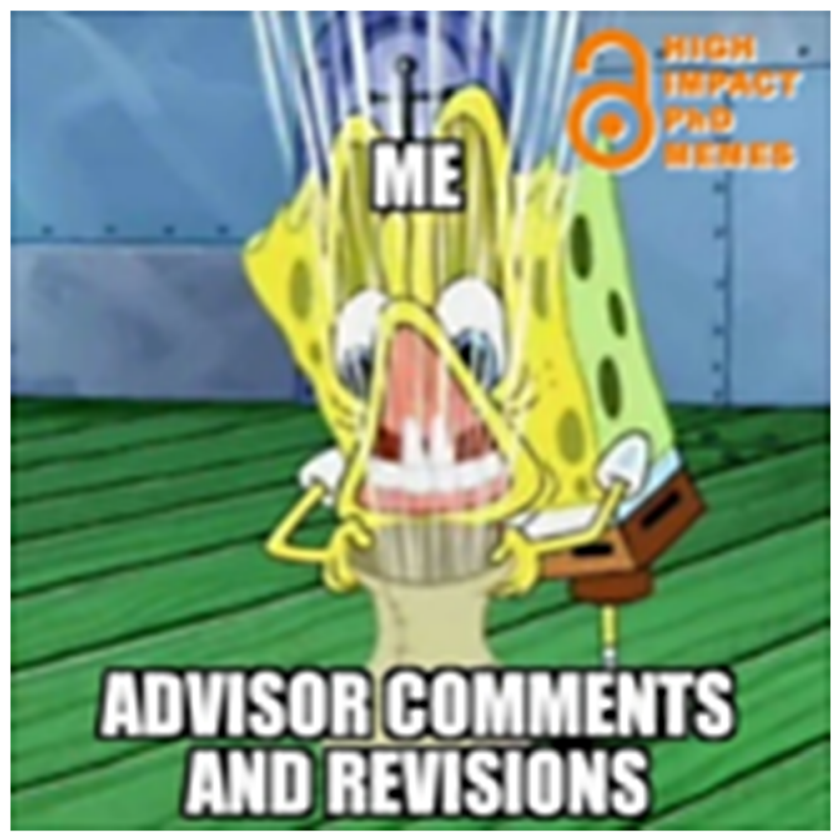

Fig. 7 Meme of Spongebob 
" So you're underpaid, sleep-deprived, have no time for hobby, spend years working on your thesis and you know that no one will read it?"

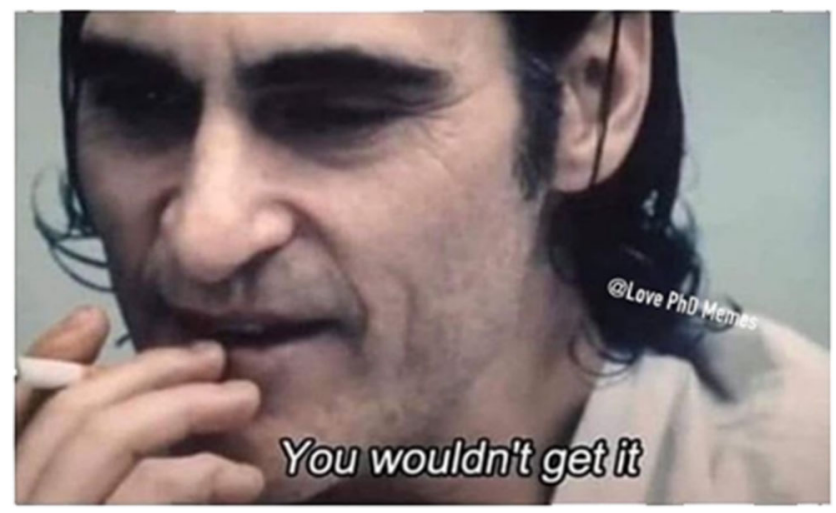

Fig. 8 Meme of The Joker

The implicit meaning of the choice of this character is to compare, in the common imagination, the choice of an underpaid, tiring and unsatisfactory job like the search for a choice result of "madness".

Also in the sample of $\mathrm{PhD}$ memes on Instagram there is a frequent use of cartoon characters. Even in these cases, the choice is not accidental. There is frequent use of the characters of The Simpson, especially of the figure of Homer, father of this average American family (Figs. 9 and 10).

Here a cultural aspect emerges, as Homer in Western culture is always seen as dumb, uneducated, weak in character and morally unprincipled person. But it also embodies the scepticism that can be declined in the context of the $\mathrm{PhD}$ as a doubtful attitude towards the right way to face the academic career. The humorous element, in this case, would reside precisely in the choice of this figure, the emblem par excellence of comedy and denunciation.

Another recurring character chosen in Instagram's $\mathrm{PhD}$ meme is Spongebob, as shown in the Fig. 11:

The use of Spongebob for $\mathrm{PhD}$ memes has a double value:

1. the sponge is an object that absorbs most of the liquid substances, as well as the PhDs for their desire to learn continuously, absorb concepts;

2. in Western culture, every character in the Spongebob cartoon represents a capital sin. In the specific case, Spongebob represents lust, understood not in a negative sense but as excessive love for others, which is declined as an excessive passion for the work that takes place.

The analysis shows a further function of humor mediated by communication through memes, depending on two different social networks taken into consideration. The aim is the same, that is the complaint against a complex and precarious career path, but the different emotions 
Nobody:

PhD Student: what if I had made a mistake in those 5-y old analyses

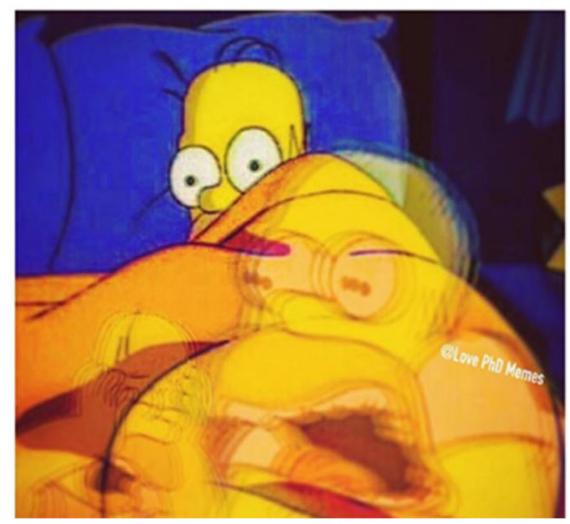

Me, enjoying my guilty pleasure of searching my own name in PubMed just to see how my publications are doing

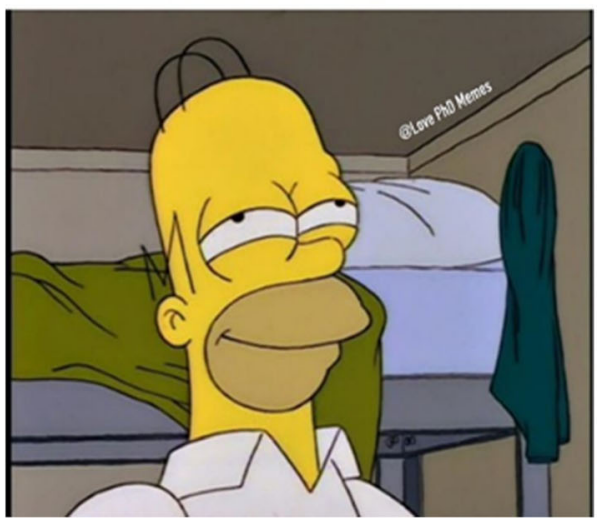

Fig. 9-10 Meme of Homer Simpson

detected in relation to the two social networks, suggests different styles of humour meme on Phd. In fact, taking up the model of Martin et al. [36] and Catanescu \& Tom [19], the "affiliative" style of humor mainly expresses positivity, therefore joy, because the intent is to facilitate the relationship with the audience. Negativity, on the other hand, depends on two other styles: "self-defeating" and "aggressiveness". Self-defeating has the function of entertaining the audience by denigrating the situation at their own expense. In this case, memes

\section{Friend: "so when are you getting a} *real* job?"

PhD student:

"wHEn ArE yOU geTTing a ReAL jOB"

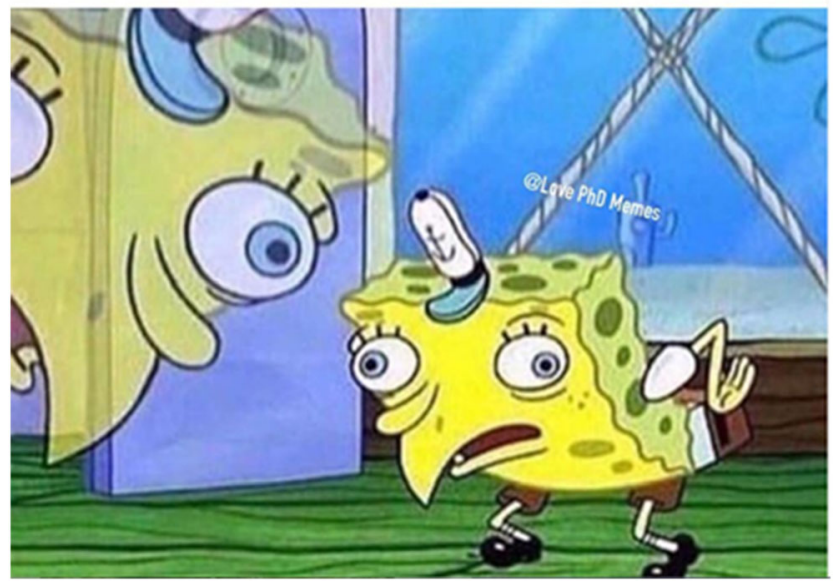

Fig. 11 Meme of Spongebob 
arouse sadness. On the contrary, aggression is the style of humor that aims to entertain without worry about hitting others too much. These last two styles of meme humor did not emerge from AI detection, that simply extracted joy and therefore positive and neutral emotionality.

However, there are differences between shared / created PhD memes on Facebook or Instagram. A first difference is at the numerical level: the $\mathrm{PhD}$ memes on Facebook are slightly larger than those on Instagram. On Instagram there are $\mathrm{PhD}$ memes consisting of text only. This also emerges from the construction of the PhD memes: on Instagram, in fact, we note the construction of longer texts compared to Facebook. The issues addressed are also different. In the PhD meme of Instagram, the humor is more oriented to the same figure of the doctoral student or academic, instead on Facebook, the relationship between supervisor and graduate student or graduate student and journals in which it is published is most affected. This also explains the difference in prevailing emotions. In Instagram memes the humor of the graduate student figure emerges as proud, strongly passionate and superb. On Facebook, on the other hand, memes focus on the non-functionality of the system, having.

This determines the communication of a different humorous function than the memetics of the two social networks: while Facebook aims to denounce through memetic humor, Instagram denounces the hierarchization of an educational context, such as the academic one. This reporting function of $\mathrm{PhD}$ meme communication act emerges above all from the Emotional Analysis and the prevalence of neutrality and the anger. The visual part is a means to mitigate the discourse meanings. Humor and imitation strategies arise in the contrast between expected/ unexpected or known/unknown: generally, it is expected that a famous character behave in a certain way, instead it is integrated in a contextual unexpected framework known. The main features of the $\mathrm{PhD}$ memes can be summarized in the following taxonomy (Table 1):

In summary, the issues addressed are an element of difference between Facebook and Instagram. In the $\mathrm{PhD}$ meme of Instagram the humor is more oriented to the same figure of the doctoral student or academic, instead on Facebook the relationship between supervisor and graduate student or graduate student and journals in which it is published is most affected. This also explains the difference in prevailing emotions.

Table 1 Taxonomy of $\mathrm{PhD}$ memes

\begin{tabular}{|l|l|l|l|l|} 
Topics & $\begin{array}{l}\text { Relationship } \\
\text { supervisors }\end{array} \quad$ with & Difficulty of publication & $\begin{array}{l}\text { Uncertainty for the } \\
\text { future of work }\end{array}$ & $\begin{array}{c}\text { The pride of the } \\
\text { doctoral student }\end{array}$ \\
\hline $\begin{array}{l}\text { Subject of } \\
\text { images }\end{array}$ & $\begin{array}{l}\text { Main character of Tv series } \\
\text { or Films }\end{array}$ & Cartoons Characters & Animals & $\begin{array}{c}\text { Recent movie } \\
\text { characters; cartoon } \\
\text { characters }\end{array}$ \\
\hline Emotions & No Emotions & Anger/Fear & Anger/Sadness & Joy/ Sadness \\
\hline $\begin{array}{l}\text { Rethorical } \\
\text { Strategies }\end{array}$ & Intensifiers Vs Attenuators & Bad words (Intensifiers) & Dialogues & Bad Words \\
\hline
\end{tabular}




\section{Discussion and conclusion}

The present research was inspired by a main pupose of understanding how the online functions and practices of humor signification are featured considering both linguistic and visual aspects within humoristic communication of $\mathrm{PhD}$ students throught ironic memes.

In particular it has a twofold goals: a) analyzing which differences emerged in terms of functions and emotions between humor in $\mathrm{PhD}$ Memes on Facebook and Instagram by means of 'dia-textual' analysis; b) performing a fine-grained qualitative analysis about rhetorical aspects based on linguistic and visual elements of Phd Memes in order to contribute to the field of humor automatic detection.

To satisfy these purposes, 70 memes about the $\mathrm{PhD}$ were extracted and collected from Instagram and Facebook. The $\mathrm{PhD}$ memes were analyzed in two levels: the quanti-qualitative, aiming to detect the semi-automatic emotional involvement, expression of humor in "meme discourses"; the semiotic analysis of meme images to enlarge the understanding on which can be possible incongruences in the classification of $\mathrm{PhD}$ humor. The virtual context, but in particular the image, conveys a representation of the academic career and, specifically of the doctoral course, which is often obscured in the offline environment, due to the uncertainty of the academic career, the Phds lose interest in pursuing, after the doctorate, the career path within the academy [52].

The virtual context also changes the way we use humorous techniques. Most rhetorical techniques such as absurdity or imitation, with memes precisely, take on a visual form rather than an oral one.

The research shows that humor in the context of $\mathrm{PhD}$ memes is based on two levels: a cognitive first linked to the perception of something unexpected and a second emotional level, which explains the presence of negative emotions such as fear. The difference between the two social networks is in terms of emotional significance with a predominantly neutral and negative distribution on Facebook and positive on Instagram. This determines the communication of a different humorous function than the memetics of the two social networks: while Facebook aims to complain through memetic humor, Instagram complain the hierarchization of an educational context, such as the academic one.

This reporting function of $\mathrm{PhD}$ meme communication act emerges above all from the manual emotional coding where also negative emotions were observed. The visual part is a means to mitigate the discourse meanings. Humor and imitation strategies arise in the contrast between expected/unexpected or known/unknown: generally, it is expected that a famous character behave in a certain way, instead it is integrated in a contextual unexpected framework known.

Starting from this contrast between expected and unexpected, we propose a qualitative research, with the aim of supporting the automatic detection of the emotionality of humor in $\mathrm{PhD}$ meme on Facebook and Instagram. It is proposed, therefore, the semiotic analysis of images as a methodology that allows to trace meanings within visual objects, like images of $\mathrm{PhD}$ memes. The analysis shows a further function of humor mediated by communication through memes, depending on two different social networks taken into consideration. The aim is the same, that is a kind of online social sharing of emotions [20] consisting in the complaint against a complex and precarious career path. Other typical functions especially of memes with negative emotionality, such as sadness, is ridiculing the figure of the Phd, which must struggle with a precarious working environment, the relationship with the supervisors, the difficulties in publishing the papers and the post-doc uncertainty. In addition, negativity has two functions: 
"self-defeating" and "aggressiveness". Self-defeating has the function of entertaining the audience by denigrating the situation at their own expenses. In this case, memes arouse sadness. On the contrary, aggression is the style of humor that aims to entertain without worry about hitting others too much.

But there are differences between shared/created $\mathrm{PhD}$ memes on Facebook or Instagram. A first difference is at the numerical level: the $\mathrm{PhD}$ memes on Facebook are slightly larger than those on Instagram. On Instagram there are $\mathrm{PhD}$ memes consisting of text only. This also emerges from the construction of the PhD memes: on Instagram, in fact, we note the construction of longer texts compared to Facebook. The issues addressed are also different. In the $\mathrm{PhD}$ meme of Instagram, the humor is more oriented to the same figure of the doctoral student or academic, instead on Facebook, the relationship between supervisor and graduate student or graduate student and journals in which it is published are most affected. This can also explain the difference in prevailing emotions. In Instagram memes, the humor of the graduate student figure emerges as proud, strongly passionate and superb. On Facebook, on the other hand, memes focus on the non-functionality of the 'academic' system.

One of the limitations of the research concerns the prevalence of neutrality output. The software does not allow, in case of neutrality, to see a sentence level analysis able to understand if neutrality is given by the absence of sentiment or as a juxtaposition of positive and negative emotions, an aspect that will be evaluated as a future perspective. In addition, among the future perspectives, a comparison of the current results of the study with other sources and with a larger sample will be provided.

\section{References}

1. Alvarado MB (2006) "Las marcas de la ironía". Interlingüística 16:151-161

2. Alvarado MB (2009) Ironía y cortesía. In: En Ruiz Gurillo L, Padilla X (eds) Dime cómo ironizas y te diré quién eres: una aproximación pragmática a la ironía. Peter Lang, Frankfurt, pp 333-345

3. Alvarado MB (2010) Las fórmulas rutinarias del español: teoría y aplicaciones. Peter Lang, Frankfurt

4. Alvarado MB (2012) El humor en los enunciados irónicos conversacionales. Oralia. 15:63-76

5. Attardo S (2001a) Humorous texts: a semantic and pragmatic analysis. Mouton De Gruyter, Berlin

6. Attardo S (2001b) Humor and irony in interaction: from mode adoption to failure of detection. In: Anolli L, Ciceri R, Riva G (eds) Say not to say: new perspectives on miscommunication, pp 166-186

7. Attardo S (2008) A primer for the linguistics of humor. In: Raskin V (ed) The primer of humor research. Mouton de Gruyter, Berlin

8. Attardo S, Raskin V (1991) Script theory revis(it)ed: joke similarity and joke representation model. HUMOR: International Journal of Humor Research 4:293-347

9. Barbotti I (2015) Instagram marketing: immagini, brand, community, relazioni per il turismo, eventi. HOEPLI EDITORE

10. Berger AA (1976) Laughing matter: a symposium: anatomy of the joke. J Commun 26(3):113-115

11. Berger AA (1993) An anatomy of humor. Transaction Publishers, New Brunswick

12. Bergson H (1900) Le rire, Paris (tr. it. Il riso, Roma-Bari, Laterza, 1994)

13. Bergson, H. (1950). Le rire, essai sur la signification du comique. Psychological Review 8(1):98-99. https://doi.org/10.1037/h0069028

14. Bergson H (2008) Laughter: an essay on the meaning of the comic. Translated by C. Brereton and F. Rothwell. Original ed. 1900. Arc Manor, Rockville

15. Berlo DK (1960) The process of communication: an introduction to theory and practice. Holt Rinehart and Winston, New York

16. Biondi G, Franzoni V, Poggioni V (2017) A deep learning semantic approach to emotion recognition using the IBM watson bluemix alchemy language. In: International conference on computational science and its applications. Springer, Cham, pp 718-729

17. Buijzen M, Valkenburg PM (2004) Developing a typology of humor in audiovisual media. Media Psychol 6(2):147-167 
18. Byrd G (2016) IEEE/IBM Watson student showcase. Computer 49(1):102-104

19. Catanescu C, Tom G (2001) Types of humor in television and magazine advertising. Review of BusinessSaint Johns University 22(1):92-95

20. Choi M, Toma CL (2014) Social sharing through interpersonal media: patterns and effects on emotional well-being. Comput Hum Behav 36:530-541

21. D’Errico F, Poggi I (2016) “The bitter laughter". When parody is a moral and affective priming in political persuasion. Frontiers in Psychology 7:1144

22. D'Errico F, Poggi I, Vincze L (2012) Discrediting signals. A model of social evaluation to study discrediting moves in political debates. Journal on Multimodal User Interfaces 6(3-4):163-178

23. Dawkins R (1976) The selfish gene. Oxford University Press, Oxford

24. De Koning E, Weiss RL (2002) The relational humor inventory: functions of humor in close relationships. Am J Fam Ther 30(1):1-18

25. Freud S (1905) Der Witz und seine Beziehung zum Unbewußten, (tr. it. Il motto di spirito e la sua relazione con l'inconscio, Torino, Boringhieri, 1975)

26. Greimas AJ (1991) Semiotica figurativa e semiotica plastica, trad. it. L. corrain e M. Valenti (a cura di), Leggere l'opera d'arte. Dal figurativo all'astratto, Bologna, esculapio

27. Grice P (1975) Logic and conversation in Syntax and semantics 3: Speech acts, a cura di P. Cole. Academic Press, New York, pp 41-58. trad. it. a cura di G. Moro, Logica e Conversazione, Il Mulino, Bologna 1993, pp 55-77

28. Hay J (2000) Functions of humor in the conversation of men and women. J Pragmat 32:709-742

29. Herzig J, Shmueli-Scheuer M, Konopnicki D (2017) Emotion detection from text via ensemble classification using word embeddings. In: Proceedings of the ACM SIGIR international conference on theory of information retrieval, pp 269-272

30. Holmes J (2000) Politeness, power and provocation: how humor functions in the workplace. Discourse Stud 2(159):185

31. Iannella A (2018) Digital authentic learning: introdurre alla tone analysis per favorire un pensiero critico digitale. Thamyris, nova series: Revista de Didáctica de Cultura Clásica, Griego y Latín 9:319-336

32. Johann M, Bülow L (2019) One does not simply create a meme: conditions for the diffusion of internet memes. Int J Commun 13:23

33. Levecque K, Anseel F, De Beuckelaer A, Van der Heyden J, Gisle L (2017) Work organization and mental health problems in PhD students. Res Policy 46(4):868-879

34. Mangold WG, Faulds DJ (2009) Social media: the new hybrid element of the promotion mix. Business Horizons 52(4):357-365

35. Manuti A, Mininni G (2017) A rose is more than a rose ... the diatextual. Constitution of subjects and objects. De Gruyter Mouton 37:243-263

36. Martin RA, Puhlik-Doris P, Larsen G, Gray J, Weir K (2003) Individual differences in uses of humor and their relation to psychological well-being: development of the humor styles questionnaire. J Res Pers 37(1): $48-75$

37. McGhee PE (1971) Cognitive development and children's comprehension of humor. Child Dev 42:123138

38. McGhee PE (1976) Laughing matter: a symposium: sex differences in children's humor. J Commun 26(3): 176-189

39. McGhee PE (1979) Humor: its origin and development. Freeman, San Francisco

40. Meyer JC (2000) Humor as a double-edged sword: four functions of humor in communication. Communication Theory 10:310-331

41. Mihalcea R, Strapparava C (2006) Learning to laugh (automatically): computational models for humor recognition. Comput Intell 22(2):126-142

42. Mininni G (2013) Psicologia culturale discorsiva. Franco Angeli, Milano

43. Nijholt A, Stock O, Dix A, Morkes J (2003) Humor modeling in the interface. Extended abstracts on human factors in computing systems - CHI '03. https://doi.org/10.1145/765891.766143

44. Novielli N, Calefato F, Lanubile F (2015) The challenges of sentiment detection in the social programmer ecosystem. In: Proceedings of the 7th international workshop on social software engineering. ACM, pp 3340

45. Ortega MBA (2013) An approach to verbal humor in interaction. Social Behavioral Sciences 95:594-603

46. Osterroth A (2015) Das Internet-Meme als Sprache-Bild-Text. Image 22:26-46

47. Pang B, Lee L (2008) Opinion mining and sentiment analysis. Foundations and Trends in Information Retrieval 2:1-135. https://doi.org/10.1561/1500000011

48. Papapicco C, Mininni G (2019) Twitter culture: irony comes faster than tourist mobility. J Tour Cult Chang: $1-12$ 
49. Poggi I, D'Errico F (2010) The mental ingredients of bitterness. Journal on multimodal user interfaces 3(12):79-86

50. Poggi I, D'Errico F, Vincze L (2013) Comments by words, face and body. Journal on Multimodal User Interfaces 7(1-2):67-78

51. Raskin V (1985) Semantic mechanisms of humor. D. Reidel, Dordrecht

52. Roach M, Sauermann H (2017) The declining interest in an academic career. PLoS One 12(9):23

53. Rothwell JD (2010) In the company of others: an introduction to communication. Oxford University Press, Oxford

54. Russell JA (2009) Emotion, core affect, and psychological construction. Cognit Emot 23(7):1259-1283

55. Scardigno R, Mininni G (2020) The rhetoric side of fake news: a new weapon for anti-politics? World Futures 76(2):81-101. https://doi.org/10.1080/02604027.2019.1703158

56. Shifman L (2014) The cultural logic of photo-based meme genres. J Vis Cult 13(3):340-358

57. Skakni I, Calatrava Moreno MDC, Seuba MC, McAlpine L (2019) Hanging tough: post-PhD researchers dealing with career uncertainty. High Educ Res Dev 38(7):1489-1503

58. Stock O, Strapparava C, Nijholt A (2002) The April Fools' day workshop on computational humour. Trento: Proceedings of the twentieth Twente Workshop on Language Technology

59. Taecharungroj V, Nueangjamnong P (2015) Humour 2.0: styles and types of humour and virality of memes on Facebook. Journal of Creative Communications 10(3):288-302

60. Turkle S (2005) The second self: computers and the human Spirit. MIT Press, Cambridge https://doi. org $/ 10.7551 / \mathrm{mitpress} / 6115.001 .0001$

61. Van Leeuwen T (2000) Semiotics and iconography. In: van Leeuwen T, Jewitt C (eds) Handbook of visual analysis. Sage, London, pp 92-118

62. Veatch TC (1998) A theory of humor. Humor 11:163-215

63. Wiggins BE (2016) Crimea River: directionality in memes from the Russia-Ukraine conflict. Int J Commun 10(35):451-485

64. Yus F (1996) La Teoría de la Relevancia y la estrategia humorística de la incongruencia-resolución. Pragmalingǘ́stica 3-4:497-508

Publisher's note Springer Nature remains neutral with regard to jurisdictional claims in published maps and institutional affiliations. 